\title{
Under-Five Mortality in Nigeria; Findings from a Nationwide Survey
}

\author{
Azuike EC ${ }^{1 *}$, Umeh UM ${ }^{1}$, Udigwe IB ${ }^{2}$, Enwonwu KG ${ }^{2}$, Arua NE ${ }^{2}$, Amah $\mathrm{CC}^{3}$, Aniemena RC ${ }^{2}$ \\ Okafor $\mathrm{KC}^{4}$, Ilika $\mathbf{F}^{5}$ \\ ${ }^{1}$ Department of Community Medicine and Primary Healthcare, Chukwuemeka Odumegwu Ojukwu University/ \\ University Teaching Hospital, Awka, Nigeria \\ ${ }^{2}$ Department of Community Medicine and Primary Healthcare, Nnamdi Azikiwe University Teaching Hospital, \\ Nnewi, Nigeria \\ ${ }^{3}$ Department of Paediatric Surgery, University of Nigeria/University of Nigeria Teaching Hospital, Enugu, \\ Nigeria \\ ${ }^{4}$ Health Research and Policy Development Group, Abuja, Nigeria \\ ${ }^{5}$ Health Policy Plus, Nigeria
}

*Corresponding Author: Azuike EC, Department of Community Medicine and Primary Healthcare, Chukwuemeka Odumegwu Ojukwu University/University Teaching Hospital, Awka, Nigeria. Email: emmanazuike@yahoo.com

\begin{abstract}
Background: One of the targets of the Sustainable Development Goals (SDG) is to reduce under-five mortality to 25 deaths per 1,000 live births by 2030. Unfortunately, most of the Sub-saharan countries are lagging behind. Nigeria is one of such countries with an under-five mortality rate of 128 per 1,000 live births. This calls for serious concerns. There is need to introduce measures to stem the tide. The aim of this study was to identify factors that increase the odds of under-five mortality in Nigeria.
\end{abstract}

Methodology: This was a population-based, cross-sectional survey covering the country of Nigeria. A total of 119,386 under-five children were considered in the study. The sampling frame for the survey was the list of Enumeration Areas (EAs) prepared for the 2006 Population Census of the Federal Republic of Nigeria, provided by the National Population Commission. We conducted secondary analysis of the data collected during the 2013 Nigeria Demographic and Health Survey. Univariable logistic regression analysis was done to identify possible determinants of under-five mortality. In order to control for other variables in the model, we conducted multivariable logistic regression which included only variables that were significant in the univariable analysis.

Results: Following multivariate analysis a number of determinants of under-five mortality were identified. They include: Geo-political zones of the children, Gender, Mother's educational level, Mother's number of births in the preceding 5 years, Mother's marital status, Maternal age, Mother's type offamily planning method, Child's birth order, Family size, Family wealth index and Place of residence (urban/rural).

Conclusion: Multiple logistic regression has enabled us to identify important determinants of under-five mortality in Nigeria. We recommend that policy makers should consider the determinants as they design interventions to combat under-five mortality.

Keywords: Under-five mortality, Nigeria, Nationwide

\section{INTRODUCTION}

Under-five mortality rate is the probability (expressed as a rate per 1,000 live births) of a child born in a specified year dying before reaching the age of five if subject to current agespecific mortality rates.[1] In plain English, under-five mortality is the death of a child before his/her $5^{\text {th }}$ birthday. One of the targets of the Sustainable Development Goals (SDG) is to reduce under-five mortality to 25 deaths per 1,000 live births by 2030.[2] According to UNICEF, in more than a quarter of all countries urgent action is needed to accelerate reductions in child mortality to reach the SDG targets on 
ending preventable child deaths by 2030. [2] Of 195 countries analysed, 30 countries will need to more than double their current rate of reduction to achieve the target on time. These countries can be found in most regions of the world, but roughly two-thirds of the countries at risk of missing the SDG target are in sub-Saharan Africa. ${ }^{2}$ Nigeria is among the countries that will not achieve the SDG on under-five mortality by 2050 if current trends prevail. The 2018 underfive mortality rate in Nigeria (as reported by UNICEF) was 138 per 1,000 live births. [2] This is a far cry from the SDG target which is 25 per 1,000 live births.

In order to reduce under-five mortality, it is important to identify factors that predispose children to under-five mortality. Identifying such factors will guide policy making and implementation. Over time several factors have crystallized from studies as possible determinants of under-five mortality. A number of studies have reported that maternal education is a determinant of under-five mortality. The studies revealed that under-five mortality was higher among children whose mothers had little or no formal education compared with those whose mothers had higher education. [3,4] The importance of maternal education is based on the fact that education increases a mother's level of knowledge and skills, thus enabling her to effectively understand and utilize available information and resources critical for child health and survival. Maternal age has also been reported to affect under-five mortality.[5,6] Birth order has been reported to affect under-five mortality. Some studies reported that higher birth order increased the odds of under-five mortality $[7,8]$, while some other studies reported that birth order had no effect on under-five mortality. $[9,10]$ Similarly, gender has been shown to affect underfive mortality. A study in Kenya reported that under-five mortality was more likely in males[11] while another study in India reported that females were more likely to experience under-five mortality.[3] The effect of socioeconomic status on under-five mortality has been reported by some studies. A study in Nigeria reported higher odds of under-five mortality among the poorest households compared with the richest households.[12] On the contrary, a national study conducted in Tanzania did not find a significant effect of household socioeconomic status on infant and under-five mortality[8]. It is important to note that most of the studies mentioned never controlled for possible confounding factors. There is need to rule out possible confounders to identify true determinants of under-five mortality. The aim of this study therefore, is to identify determinants of under-five mortality in Nigeria after controlling for confounders.

\section{Methodology}

\subsection{Setting}

Nigeria lies on the west coast of Africa between latitudes $4^{\circ} 16^{\prime}$ and $13^{\circ} 53^{\prime}$ north and longitudes $2^{\circ} 40^{\prime}$ and $14^{\circ} 41^{\prime}$ east.[13] Nigeria occupies approximately 923,768 square kilometers of land stretching from the Gulf of Guinea on the Atlantic coast in the south to the fringes of the Sahara Desert in the north. The territorial boundaries are defined by the republics of Niger and Chad in the north, the Republic of Cameroon on the east, and the Republic of Benin on the west. Nigeria is the most populous country in Africa and the 14th largest in land mass. According to Nigeria's 2006 Population and Housing Census, the country's population was $140,431,790$ as of 2006.[13] Nigeria is yet to conduct a national census after the 2006 Census, but 2019 estimate by the World Population Review placed the country's population at 199,566.817. [14] Presently, Nigeria is made up of 36 states and a Federal Capital Territory, grouped into six geopolitical zones: North Central, North East, North West, South East, South South, and South West.

\subsection{Study Design}

This is a secondary analysis of data from a nationwide population-based cross sectional survey called Nigeria Demographic and Health Survey (NDHS) 2013. The NDHS 2013 was done by the National Population Commission (NPC) of Nigeria with financial and technical assistance from ICF International through the USAID-funded MEASURE DHS program. This paper investigated the roles of some factors in Under-five mortality in Nigeria.

\subsection{Sampling Technique}

A detailed explanation of the sampling technique applied is in the full report of the 2013 NDHS. [13] The sample for the 2013 NDHS was nationally representative and covered the entire population residing in non-institutional dwelling units in the country. The sampling frame for the survey was the list of Enumeration Areas (EAs) prepared for the 2006 Population Census of the Federal Republic of Nigeria, provided by the National Population Commission. Population and health indicator estimates at the national, zonal, and state levels were provided based on the design of the sample. An important feature of the 
sample design was that it allowed for specific indicators to be calculated for each of the six geopolitical zones, 36 states, and the Federal Capital Territory, Abuja. Nigeria operates a three-tier levels of government: Federal, State and Local Government Area (LGA). Each LGA is divided into localities. These 3 levels of government are administrative units. In addition to these administrative units, during the 2006 population census, each locality was subdivided into census Enumeration Areas (EAs).

The Primary Sampling Unit (PSU), referred to as a cluster in the 2013 NDHS, is defined on the basis of EAs from the 2006 EA census frame. The 2013 NDHS sample was selected using a stratified three-stage cluster design consisting of 904 clusters, 372 in urban areas and 532 in rural areas. A representative sample of 40,680 households was selected for the survey, with a minimum target of 943 completed interviews per state. In each cluster, 45 households were selected. In each household, all women aged 1549 years were eligible to be interviewed. It was different for the men. All men age 15-49 years in half of the households were eligible to be interviewed.

\subsection{Data Collection}

The final report of 2013 NDHS contains detailed information on the data collection and questionnaires. [13] Data collection for the NDHS 2013 used three questionnaires: the Household Questionnaire, the Woman's Questionnaire, and the Man's Questionnaire. The content of these questionnaires was based on model questionnaires developed by the MEASURE DHS programme. The model questionnaires were modified according to the country's requirements, in consultation with a broad spectrum of government ministries and agencies, non-governmental organizations, and international donors, to reflect relevant issues. Data collection commenced in February 2013 and ended in June 2013.

\subsection{Ethical Considerations}

Ethical approval for this project was obtained from the ethical committee of ICF at Calverton, Maryland, USA and National Ethics Committee in the Federal Ministry of Health, Abuja, Nigeria.

\subsection{Outcome Variable}

The outcome variable is death before fifth birthday (under-five mortality).

\subsection{Explanatory Variables}

Selection of variables was based on previous studies.[15,16,17,18,19,20] The following factors were considered in the study: Geopolitical zone of residence, gender of the children, maternal highest educational level, maternal number of births in the last 5 years, maternal current marital status, maternal current age, maternal current use of family planning, child's birth order, family size, family's wealth index, family's type place of residence (urban/ rural).

\subsection{Statistical Analysis}

All the explanatory (predictor) variables that were originally continuous numerical variables were re-coded into categorical variables. For ease of interpretation, some explanatory variables that were originally categorical were re-coded to reduce their groups. Descriptive analysis of both the explanatory and outcome (dependent) variables was done. Univariable binary logistic regression was used to examine the association between the individual explanatory variables and the outcome variable. Only explanatory variables that were statistically significant were incorporated into multivariable binary logistic regression. P-value $\leq 0.05$ was considered statistically significant. IBM SPSS (Statistical Package for the Social Sciences) data analysis software (version 20.0) was used for the analysis.

\section{Results}

\subsection{Sample Characteristics}

A total of 119,386 under-five children were considered in the study. Seventeen percent $(20,239)$ died before their $5^{\text {th }}$ birthday. Out of the 6 geo-political zones, the North-west had the highest population $(32.5 \%)$ while the South-east was the least represented (9.4\%). The population of males $(51.3 \%)$ was slightly higher than that of females $(48.7 \%)$. Half of the mothers of the under-five children had no education (50.9\%). Majority of the mothers (93.4\%) had less than 3 childbirths within the 5 years prior to the data collection. Majority of the mothers (92.9\%) were currently in a union or living with a man. More than half $(51 \%)$ of the mothers were older than 35 years. Majority $(84.6 \%)$ of the women were not using any family planning method. Almost half $(48.0 \%)$ of the under-five children were of the $2^{\text {nd }}$ to $4^{\text {th }}$ birth order. About two-third (66.9\%) of the children belonged to families with more than 5 household members. Close to half (46.9\%) of the under-five children's families belonged to the poor wealth index. Slightly above two-thirds $(67.5 \%)$ of the children were residing in the rural areas. (Table 1) 
Table1. Statistical Summary of variables

\begin{tabular}{|c|c|c|}
\hline Variable & Frequency & Percentage \\
\hline \multicolumn{3}{|l|}{ Geopolitical zone } \\
\hline North-Central & 16,143 & 13.5 \\
\hline North-East & 24,180 & 20.3 \\
\hline North-West & 38,757 & 32.5 \\
\hline South-East & 11,219 & 9.4 \\
\hline South-South & 14,857 & 12.4 \\
\hline South-West & 14,230 & 11.9 \\
\hline \multicolumn{3}{|l|}{ Gender of the children } \\
\hline Male & 61,287 & 51.3 \\
\hline Female & 58,099 & 48.7 \\
\hline \multicolumn{3}{|l|}{ Survival status } \\
\hline Dead & 20,239 & 17.0 \\
\hline Alive & 99,147 & 83.0 \\
\hline \multicolumn{3}{|c|}{ Mother's highest Educational Qualification } \\
\hline No education & 60,778 & 50.9 \\
\hline Primary education & 27,945 & 23.4 \\
\hline Secondary or higher education & 30,663 & 25.7 \\
\hline \multicolumn{3}{|c|}{ Maternal number of births in the last 5 years } \\
\hline Less than 3 births & 111544 & 93.4 \\
\hline Three or more births & 7842 & 6.6 \\
\hline \multicolumn{3}{|l|}{ Maternal Current marital status } \\
\hline Never in union & 985 & 0.8 \\
\hline Currently in union/living with a man & 110,948 & 92.9 \\
\hline Formerly in union/living with a man & 7,453 & 6.2 \\
\hline \multicolumn{3}{|l|}{ Maternal current age (years) } \\
\hline 20 yrs or less & 3,725 & 3.1 \\
\hline 21 to 25 years & 11,358 & 9.5 \\
\hline 26 to 30 years & 21,742 & 18.2 \\
\hline 31 to 35 years & 21,687 & 18.2 \\
\hline greater than $35 \mathrm{yrs}$ & 60,874 & 51.0 \\
\hline \multicolumn{3}{|c|}{ Maternal current use of family planning } \\
\hline None & 101,030 & 84.6 \\
\hline Traditional/Folkloric method & 6,024 & 5.0 \\
\hline Modern method & 12,332 & 10.3 \\
\hline \multicolumn{3}{|l|}{ Birth order } \\
\hline 1 & 27,451 & 23.0 \\
\hline 2 to 4 & 57,294 & 48.0 \\
\hline$\geq 5$ & 34,641 & 29.0 \\
\hline \multicolumn{3}{|l|}{ Family size } \\
\hline 1 to 5 & 39,480 & 33.1 \\
\hline greater than 5 & 79,906 & 66.9 \\
\hline \multicolumn{3}{|l|}{ Wealth index } \\
\hline Poor & 55,942 & 46.9 \\
\hline Middle & 24,594 & 20.6 \\
\hline Rich & 38,850 & 32.5 \\
\hline \multicolumn{3}{|l|}{ Residence } \\
\hline Urban & 38,786 & 32.5 \\
\hline Rural & 80,600 & 67.5 \\
\hline
\end{tabular}

\subsection{Univariable Analysis}

Table 2 shows the results of univariable (unadjusted) analysis. Before adjusting for possible confounders, the under-five children in the North-east were $100 \%$ more likely to die before their fifth birthday than the children in the North-central geo-political zone. Similarly, the children in the North-west geo-political zone were $155 \%$ more likely to experience under-five mortality than those in the North-central geopolitical zone. Being female reduced the odds of under-five mortality by $13 \%$. Children whose mothers had primary education had lesser odds of under-five mortality (41\%) compared with those whose mothers had no formal education. Similarly, those whose mothers had at least secondary education had lesser odds (62\%) of 
dying before their $5^{\text {th }}$ birthday. Children whose mothers had 3 or more births in the last five years had $21 \%$ higher odds of under-five mortality than those whose mothers had less than 3 births in the last five years. Children whose mothers were in a union were $65 \%$ more likely to experience underfive mortality compared with those whose mothers were never in a union. Under-five children whose mothers were older than 35 years had $63 \%$ higher odds of dying compared with those whose mothers were less than 20 years old. Children whose mothers were using traditional/ folkloric family planning method had $112 \%$ higher odds of under-five mortality than those whose mothers were not using any family

Table2. Result of univariable logistic regression analysis for under-5 mortality

\begin{tabular}{|l|l|l|l|}
\hline Variable & OR & p-value & CI \\
\hline Region & & & \\
\hline North-Central & 1.000 & & \\
\hline North-East & 2.069 & $<0.01$ & $1.950-2.195$ \\
\hline North-West & 2.551 & $<0.01$ & $2.414-2.695$ \\
\hline South-East & 1.354 & $<0.01$ & $1.258-1.457$ \\
\hline South-South & 0.974 & 0.480 & $0.906-1.047$ \\
\hline South-West & 1.022 & 0.550 & $0.951-1.099$ \\
\hline Gender & & & \\
\hline Male & 1.000 & & \\
\hline Female & 0.874 & $<0.01$ & $0.848-0.901$ \\
\hline Maternal highest Education level & & & \\
\hline No education & 1.000 & & \\
\hline Primary education & 0.597 & $<0.01$ & $0.575-0.621$ \\
\hline Secondary or higher education & 0.383 & $<0.01$ & $0.367-0.400$ \\
\hline Maternal number of births in the last 5 years & & & \\
\hline Less than 3 & 1.000 & & \\
\hline 3 or more & 1.209 & $<0.01$ & $1.141-1.281$ \\
\hline Maternal Current marital status & & & \\
\hline Never in a union & 1.000 & & \\
\hline Currently in union/living with a man & 1.646 & $<0.01$ & $1.348-2.009$ \\
\hline Formerly in union/living with a man & 1.654 & $<0.01$ & $1.343-2.036$ \\
\hline Maternal age (years) & & & \\
\hline$\leq 20$ & 1.000 & & \\
\hline 21 to 25 & 1.020 & 0.732 & $0.913-1.139$ \\
\hline 26 to 30 & 1.136 & 0.015 & $1.025-1.260$ \\
\hline 31 to 35 & 1.302 & $<0.01$ & $1.174-1.443$ \\
\hline$>35$ & 1.633 & $<0.01$ & $1.480-1.802$ \\
\hline Family planning & & & \\
\hline None & 1.000 & & \\
\hline Traditional/Folkloric method & 2.116 & $<0.01$ & $1.989-2.252$ \\
\hline Modern method & 1.001 & 0.983 & $0.902-1.112$ \\
\hline Birth order & & & \\
\hline 1 & 1.000 & & \\
\hline 2 to 4 & 0.919 & $<0.01$ & $0.884-0.955$ \\
\hline$\geq 5$ & 1.121 & $<0.01$ & $1.075-1.168$ \\
\hline Family size & & & \\
\hline 1 to 5 & 1.000 & & \\
\hline$>5$ & 0.870 & $<0.01$ & $0.843-0.898$ \\
\hline Wealth index & & & \\
\hline Poor & 1.000 & & \\
\hline Middle & 1.703 & $<0.01$ & $1.635-1.773$ \\
\hline & & & \\
\hline
\end{tabular}

planning method. Children who were of the " $5^{\text {th }}$ or more" birth order were $12 \%$ more likely to die before their $5^{\text {th }}$ birthday compared with those who were the first. Family size of greater than five was protective against under-five mortality by $13 \%$ compared with family size of " 1 to 5 ". Belonging to the middle wealth index increased the odds of under-five mortality by $70 \%$ while belonging to the rich wealth index reduced the odds of under-five mortality by $33 \%$ compared with those who belong to the poor wealth index. The under-five children in the rural areas were $69 \%$ more likely to die before their $5^{\text {th }}$ birthday compared with those in the urban areas. 


\begin{tabular}{|l|l|l|l|}
\hline Rich & 0.670 & $<0.01$ & $0.638-0.703$ \\
\hline Residence & & & \\
\hline Urban & 1.000 & & \\
\hline Rural & 1.686 & $<0.01$ & $1.628-1.746$ \\
\hline
\end{tabular}

\subsection{Multivariable Analysis}

Following univariable analysis, multivariable analysis was conducted. Multivariable analysis involved control for all factors that were significant in univariable analysis in order to rule out possible confounders. The findings are shown in table 3. The geo-political zones of the children retained significance after multivariable analysis. The children in the North-west retained highest likelihood of under-five mortality (208\%) compared with the North-central. Closely behind them were children in the Northeast who had $73 \%$ higher odds of under-five mortality compared with the children in the North-central. Similarly, children in the Southeast and the South-west had higher chances of under-five mortality than children in the Northcentral. Female gender conferred protection against under-five mortality by $13 \%$. Children whose mothers had primary education were $13 \%$ less likely to die before their $5^{\text {th }}$ birthday while those whose mothers had "secondary or higher" education were $32 \%$ less likely to die before their $5^{\text {th }}$ birthday compared with those whose mothers had no formal education. After adjusting for confounders, children whose mothers had 3 or more births in the last 5 years had higher odds (43\%) of under-five mortality compared with those whose mothers had less than 3 births in the last 5 years. Children whose mothers were "currently in a union" were less likely (28\%) to experience under-five mortality compared with those whose mothers were never in a union. Maternal age higher than 35 years increased the odds of under-five mortality by $189 \%$ compared with maternal less than 20 years. Children whose mothers were using traditional/folkloric family planning method were $27 \%$ more likely to die before their $5^{\text {th }}$ birthday compared with those whose mothers were not using any family planning method. Children who were of the " 5 th or more" birth order had $24 \%$ less odds of underfive mortality compared with children who belong to the $1^{\text {st }}$ birth order. Belonging to a household with more than 5 members, conferred $37 \%$ protection against under-five mortality, compared with those whose households had 1 to 5 family members. Rich wealth index under-five children had $18 \%$ lesser chances of under-five mortality compared with the poor wealth index under-five children. Children who live in the rural area had $18 \%$ higher odds of under-five mortality.

Table3. Result of multivariable logistic regression analysis for under-5 mortality

\begin{tabular}{|l|l|l|l|}
\hline Variable & OR & p-value & CI \\
\hline Region & & & \\
\hline North-Central & 1.000 & & \\
\hline North-East & 1.729 & $<0.01$ & $1.624-1.841$ \\
\hline North-West & 2.079 & $<0.01$ & $1.958-2.207$ \\
\hline South-East & 1.398 & $<0.01$ & $1.293-1.511$ \\
\hline South-South & 1.027 & 0.492 & $0.952-1.107$ \\
\hline South-West & 1.172 & $<0.01$ & 1.086 \\
\hline Gender & & & 1.265 \\
\hline Male & 1.000 & & \\
\hline Female & 0.869 & $<0.01$ & $0.842-0.896$ \\
\hline Maternal highest Education level & & & \\
\hline No education & 1.000 & & \\
\hline Primary education & 0.874 & $<0.01$ & $0.835-0.915$ \\
\hline Secondary or higher education & 0.677 & $<0.01$ & $0.639-0.716$ \\
\hline Maternal number of births in the last 5 years & & & \\
\hline Less than 3 & 1.000 & & \\
\hline 3 or more & 1.433 & $<0.01$ & $1.348-1.523$ \\
\hline Maternal Current marital status & & & \\
\hline Never in a union & 1.000 & & \\
\hline Currently in union/living with a man & 0.724 & 0.002 & $0.589-0.890$ \\
\hline Formerly in union/living with a man & 0.736 & 0.005 & $0.593-0.912$ \\
\hline Maternal age (years) & & & \\
\hline$\leq 20$ & 1.000 & & \\
\hline 21 to 25 & 1.286 & $<0.01$ & $1.149-1.441$ \\
\hline
\end{tabular}




\begin{tabular}{|l|l|l|l|}
\hline \multicolumn{3}{|l|}{} & \multicolumn{1}{l|}{} \\
\hline 26 to 30 & 1.741 & $<0.01$ & $1.564-1.939$ \\
\hline 31 to 35 & 2.310 & $<0.01$ & $2.073-2.575$ \\
\hline$>35$ & 2.885 & $<0.01$ & $2.599-3.203$ \\
\hline Family planning & & & \\
\hline None & 1.000 & & \\
\hline Traditional/Folkloric method & 1.266 & $<0.01$ & $1.185-1.354$ \\
\hline Modern method & 1.019 & 0.730 & $0.916-1.134$ \\
\hline Birth order & & & \\
\hline 1 & 1.000 & & \\
\hline 2 to 4 & 0.815 & $<0.01$ & $0.782-0.849$ \\
\hline$\geq 5$ & 0.757 & $<0.01$ & $0.723-0.793$ \\
\hline Family size & & & \\
\hline 1 to 5 & 1.000 & & \\
\hline$>5$ & 0.630 & $<0.01$ & $0.609-0.653$ \\
\hline Wealth index & & & \\
\hline Poor & 1.000 & & \\
\hline Middle & 1.239 & $<0.01$ & $1.184-1.297$ \\
\hline Rich & 0.816 & $<0.01$ & $0.773-0.862$ \\
\hline Residence & & & \\
\hline Urban & 1.000 & & \\
\hline Rural & 1.176 & $<0.01$ & $1.126-1.229$ \\
\hline
\end{tabular}

\section{DISCUSSION}

Multivariable analysis revealed some important determinants of under-five mortality which remained significant even after adjusting for possible confounders. The geo-political zones of the children remained statistically significant even after controlling for confounders. The children in the North-west had $108 \%$ higher odds of under-five mortality compared with those in the North-central. Children in the North-east had 73\% higher likelihood of under-five mortality compared with the North-central children. Similarly, children in the South-east and the South-west had higher odds of under-five mortality ( $40 \%$ and $17 \%$ respectively) than those in the North-central. The differences between the Geo-political zones may be as a result of sociocultural differences, differences in sanitation and uneven distribution of some amenities such as power, potable water, health facilities, etc. In Ethiopia, the odds of death before age 5 were elevated in Amhara $(\mathrm{OR}=2.02)$, Oromia $(\mathrm{OR}=1.97)$, Benishangul-Gumez $\quad(\mathrm{OR}=2.47)$, SNNP(OR=2.17) and Gambela National Regional State $(\mathrm{OR}=2.45)$ compared with Addis Ababa region controlling for other variables in the model. ${ }^{19}$ In our study, the female gender had $13 \%$ lesser odds of under-five mortality compared with the male gender, controlling for other variables in the model. A study in Ethiopia also reported higher odds of under-five mortality among males.[11] This may be as a result of the differences in the genetic makeup of males and females. In the index study, children whose mothers had "secondary or higher" education had $32 \%$ lesser odds of under-five mortality compared with those whose mothers had no formal education. Also those whose mothers had primary education had $13 \%$ lesser odds of underfive mortality compared with those whose mothers had no formal education. This agrees with the findings for several other studies. ${ }^{21,22,23}$ The effect of maternal education on child survival may be because education improves socio-economic status, improves health knowledge, increases modern attitudes towards health care and also enhances female autonomy. Another finding in our study is that children whose mothers had " 3 or more births" in the last five years had $43 \%$ higher odds of dying before their $5^{\text {th }}$ birthday compared with those whose mothers had "less than 3 birth" in the last 5 years, controlling for other variables in the equation. This may be as a result of the effect of child spacing. A study done in Nairobi Kenya reported that a preceding birth interval of "less than 18 months" was associated with a two-fold increase in mortality risk compared with lengthened intervals of "36 months or longer".[24] Also Julie Davanzo et al, reported that "controlling for other correlates of infant and child mortality, shorter intervals between pregnancy were associated with higher mortality in the children".[25]

In the index study, children whose mothers were "older than 35 years" had almost three times more likelihood (OR: 2.885) of under-five mortality compared with those whose mothers were "20 years or less". In the United States it was reported that the risk of infant mortality was nearly equal for infants born to mothers 25-29 years and 30-34 years of age.[26] But infants 
born to mothers $35-39$ years of age had $18 \%$ higher risks and those born to mothers 40-49 years of age had $69 \%$ higher risks. ${ }^{26}$ This agrees with the findings of our study. This may be explained by the genetic changes that occur in the body of a female as she grows older. These changes in the mother's body ultimately affect the offspring born at that older age. In our study, children who belong to the " $5^{\text {th }}$ or more" birth order had 24\% lesser odds of under-five mortality compared with those who are of the $1^{\text {st }}$ birth order. It has been reported that increased mortality occurs in the first birth orders because they are commonly born to very young mothers.[27] However, it must be noted that some studies have reported that higher order births were associated with increased risk of under-five mortality.[7,8,28]

The finding of lesser odds of under-five mortality among the children in larger household size in our study is surprising because one can opine that there is expected depletion of resources in large families. A study in Bangladesh had a similar finding.[29] Children in the rich wealth index households had lesser odds of under-five mortality compared with those in the poor wealth index households. Some studies have reported that poverty is implicated in many cases of child deaths. $[12,30]$ It has also been reported in Nigeria that the chances of under-five mortality was higher in the poor wealth index.[12] This may be explained by the fact that higher wealth index families are better able to purchase healthcare. Also the lower wealth index families are more prone to having under-nourished children. In addition, the higher wealth index families' decision makers are more likely to have had formal education which impacts positively on the health of the children.

Rural children had $18 \%$ higher odds of under-five compared with urban children in our study. This is consistent with the findings of several studies conducted in several sub-saharan countries. $[31,32,33]$ This disparity between the urban and rural areas has can be as a result of inequities in citing of health and health-related facilities, socioeconomic factors, socio-cultural beliefs and practices, and individual level risk factors.

At this juncture we wish to highlight some strengths and weaknesses of this type of study. This was a nationwide, population-based, crosssectional study. The sample size was also relatively large. Based on the fore-going, the findings from this study can be generalized to the general population. It is also worthy of note that the weakness of this type of study is inability to establish "causal effect". In addition, the data is a point prevalence data. One may not be able to say whether the data is time dependent thereby making "length bias" a source of concern. Another limitation of this study is the retrospective nature of the DHS data. This introduces "recall bias" in the reporting of events over the preceding 5-year period. In addition, the place of residence of some respondents at the time of the survey may have changed over the period from the date of birth of the child.

Having noted the above findings we recommend as follows: The federal government of Nigeria should partner with Non-Governmental Organizations (NGOs) to design interventions that will put into considerations determinants that have been identified. Both the federal and state governments should make efforts to balance the disparities between the urban and the rural areas while citing health-related amenities. Governors of the states in the geo-political zones that are worse-off should come together and develop regional strategy to tackle under-five mortality. There must be a reason some geo-political zones are faring better than others. Female education should be considered an emergency nationwide. Poverty eradication should also be on the front burner nationwide.

ACKNOWLEDGEMENT: The authors are grateful to the Measure DHS program for graciously releasing the data of the $2013 \mathrm{NDHS}$ at no cost to the authors.

\section{REFERENCES}

[1] Wikigender. Under five mortality rate. 2019 [cited 2019 Sep 1]. Available from: https:// www.wikigender.org/wiki/under-five-mortality -rate/

[2] United Nations Children Emergency Fund (UNICEF). Child survival and the SDGs. 2019 [cited 2019 Sep 1]. Available from: https://data. unicef.org/topic/child-survival/child-survivalsdgs/

[3] Nath DC, Land KC. Birth spacing, breastfeeding, and early child mortality in a traditional Indian society: a hazards model analysis. Soc Biolology. 1994;41(3-4):168-80.

[4] Worku Z. Factors that affect under-five mortality among South African children: analysis of the South African Demographic and Health Survey Data Set. In: Proceedings of the World Congress on Engineering and Computer Science. 2009. p. 1-3.

[5] Heiko B, Olaf M, Albrecht J, Adjima G, Gisela K. Risk factors of infant and child mortality in rural Burkina Faso. Bull World Heal Organ. 2004;82(4). 
[6] Ettarh R, Kimani J. Determinants of under-five mortality in rural and urban Kenya. Rural Remote Health. 2012;1-9.

[7] Mturi AJ. The determinants of infant and child mortality in Tanzania. Heal Policy Plan. 1995;10(4):384-94.

[8] Deribew A, Tessema F. Determinants of underfive mortality in Gilgel Gibe Field Research Center, Southwest Ethiopia. Ethiop J Heal Dev. 2007;21(2):117-24.

[9] Ronsmans C. Birth spacing and child survival in rural Senegal. Int J Epidemiol. 1996;25(5):98997.

[10] Mutisya M, Orindi B, Emina J, Zulu E YY. Is mortality among under-five children in Nairobi slums seasonal? Trop Med Int Heal 2010; 15(1) 132-139. 2010;15(1).

[11] Doctor HV. Does living in a female-headed household lower child mortality? The case of rural Nigeria. Rural Remote Health. 2011;11(1635).

[12] ICF Macro and Nigeria Population Commission (NPC). Nigeria Demographic and Health Survey 2013. 2014.

[13] World Population Review. Nigeria Population 2019. 2019 [cited 2019 Mar 23]. Available from: https://www.worldpopulationreview.com

[14] Abbas B, Streatfield Kim. A hazard logit model analysis of covariates of childhood mortality in Matlab, Bangladesh. J Biosoc Sci. 1992; 24(4):447-62.

[15] Mohammed B. Individual and environmental influence on Infant and child mortality in rural sierra leone: A multivariate analysis. J Popul Stud. 1988;12:155-85.

[16] Kayode GA, Adekanmbi VT, Uthman OA. Risk factors and a predictive model for under-five mortality in Nigeria: evidence from Nigeria demographic and health survey. 2015;

[17] Manda SO. Birth intervals, breastfeeding and determinants of childhood mortality in Malawi.e. Soc Sci Med. 1999;48(3):301-12.

[18] Bedada D. Determinant of Under-Five Child Mortality in Ethiopia. 2017;6(4):198-204.

[19] Alberto P, Guido A, Lastiri S. The Effects of Breastfeeding Exclusivity on Early Childhood Outcomes. Bull PAHO [Internet]. 1994; 28(2): S128-35. Available from: http://ajph.Apha publications.org/doi/10.2105/AJPH.2013.3017 13
[20] Maniruzzaman M, Suri HS, Kumar N, Abedin MM, Rahman MJ, El-Baz A, et al. Risk factors of neonatal mortality and child mortality in Bangladesh. J Glob Health. 2018;8(1).

[21] Lalou R. Child mortality in the urban and rural Sahel. Popul Engl Sel. 1997;9:147-68.

[22] Antai D. Regional inequalities in under-5 mortality in Nigeria: a population-based analysis of individual- and community-level determinants. 2011;1-10.

[23] Fosto JC, Cleland J, Mberu B, Mutua M, Elungata P. Birth spacing and child mortality: an analysis of prospective data from the Nairobi urban health and demographic surveillance system. J Biosoc Sci. 2013;45(6):779-98.

[24] Davanzo J, Hale L, Razzaque A, Rahman M. The effects of pregnancy spacing on infant and child mortality in Matlab, Bangladesh: How they vary by the type of pregnancy outcome that beganthe interval. Popul Stud (NY). 2008; 62(2):131-54.

[25] Friede A, Baldwin W, Rhodes P, Buehler J, Strauss L. Older maternal age and infant mortality in the United States. Obstet Gynaecol. 1988;72(2):152-7.

[26] Gubhaju B. Effects of birth order and maternal age on infant and child mortality in rural Nepal. Biol Soc. 1985;2(1):15-22.

[27] Brockerhoff M, Hewett P. Inequality of child mortality among ethnic groups in sub-Saharan Africa. 2000;78(1):30-41.

[28] Uddin J, Hossain Z. Predictors of infant mortality in a developing country. Asian J Epidemiol. 2008;1(1):1-16.

[29] Lawn J, Cousens S, Zupan J. 4 million neonatal deaths: When? Where? Why? Lancet. 2005; 365:891-900.

[30] Kenya National Bureau of Statistics. Kenya Demographic and Health Survey 2008-09. Calverton, MD: Kenya National Bureau of Statistics and ICF Macro; 2009.

[31] Houweling T, Kunst A, Moser K, Mackenbach J. Rising under-5 mortality in Africa: who bears the brunt? Trop Med Int Heal. 2006;11(8):121827.

[32] Ghana Statistical Service, Ghana Health Service IM. Ghana Demographic and Health Survey 2008. Accra: GSS, GHS, and ICF Macro; 2009.

Citation: Azuike EC, et al, Under-Five Mortality in Nigeria; Findings from a Nationwide Survey. ARC Journal of Public Health and Community Medicine.2019; 4(2):7-15. DOI: dx.doi. org/ 10.20431/2456-0596.0402002.

Copyright: (C) 2019 Authors. This is an open-access article distributed under the terms of the Creative Commons Attribution License, which permits unrestricted use, distribution, and reproduction in any medium, provided the original author and source are credited. 